\title{
Water-Mediated Collagen and Mineral Nanoparticle Interactions Guide Functional Deformation of Human Tooth Dentin
}

Jean-Baptiste Forien*, Ivo Zizak, Claudia Fleck, Ansgar Petersen, Peter Fratzl, Emil Zolotoyabko, Paul Zaslansky*

Table S1. Values of crystallite length, width and thickness reported in the literature for apatite from dentine.

\begin{tabular}{|c|c|c|c|c|c|}
\hline Authors & $\begin{array}{l}\text { Type of } \\
\text { sample }\end{array}$ & $\begin{array}{c}\text { Experimental } \\
\text { method }\end{array}$ & Crystallite length [nm] & $\begin{array}{l}\text { Crystallite widths } \\
\qquad[\mathrm{nm}]\end{array}$ & $\begin{array}{l}\text { Crystallite thickness } \\
\text { [nm] }\end{array}$ \\
\hline Bale et al., $1934^{25}$ & slab & $\mathrm{XRD}$ & 24 & - & - \\
\hline Jensen and Möller, $1948^{23}$ & powder & XRD & 20 & - & - \\
\hline Johansen and Parks, $1960^{19}$ & powder & TEM & 100 & - & $2.0-3.5$ \\
\hline Johansen, $1964^{18}$ & powder & TEM & 100 & - & - \\
\hline Voegel and Frank, $1977^{29}$ & section of ITD & TEM & - & $36.5 \pm 1.5$ & $10.3 \pm 0.3$ \\
\hline Schroeder and Frank, $1985^{15}$ & PTD & TEM & $36 \pm 1.9$ & $25.6 \pm 1.4$ & $9.8 \pm 0.7$ \\
\hline Abe et al., $1991^{20}$ & ground section & TEM & $40-60$ & - & - \\
\hline Linde and Goldberg, $1993^{21}$ & section of ITD & TEM & 60 & - & $2-3$ \\
\hline Tesch et al., $2001^{30}$ & slab & SAXS & - & - & $2.3-3.6$ \\
\hline Gawda et al., $2003^{26}$ & slab & XRD & $27.2 \pm 10.3$ & - & - \\
\hline Vieira et al., $2003^{24}$ & powder & XRD & $17.7 \pm 3.1$ & $7 \pm 1.8$ & - \\
\hline Almer and Stock, $2010^{27}$ & slab & $\mathrm{XRD}$ & 30 & - & - \\
\hline Märten et al., $2010^{8}$ & slab & SAXS & - & - & $2.0-3.5$ \\
\hline Deymier-Black et al., $2013^{28}$ & slab & $\mathrm{XRD}$ & $50 \pm 8$ & - & - \\
\hline Xue et al., $2013^{22}$ & slab & XRD & $17-50$ & $10-16$ & - \\
\hline Xue et al., $2013^{22}$ & section & TEM & - & $6.5-7$ & - \\
\hline
\end{tabular}




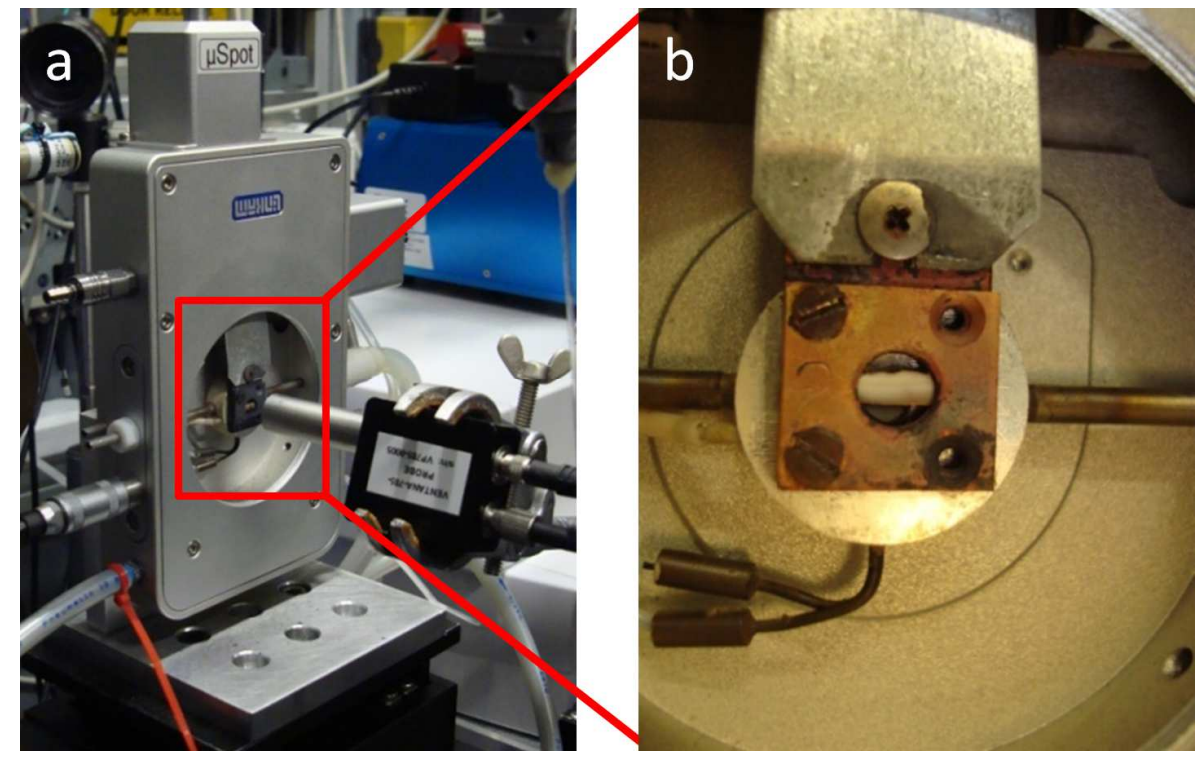

Figure S1. Optical pictures of the experimental in situ setup at mySpot beamline of the BESSY II synchrotron light source HZB - Helmholtz-Zentrum Berlin, Berlin, Germany. a The Linkam heating device used during heat treatment experiment can be observed as well as the Raman spectrometer probe. b A picture of the heating components of the oven stage showing a dentine slice sample attached to the heating plate with a $3 \mathrm{~mm}$ diameter hole allowing beam passage towards the detector.

Movie S1 and S2: 3D rendering and slices in phase-contrast enhanced tomographies of teeth imaged at $0.438 \mu \mathrm{m}$ spatial resolution before (Movie S1) and after (Movie S2) heat treatment. 